\title{
O centro de Atenção Psicossocial e as estratégias para inserção da família*
}

\author{
CENTERS OF PSYCHO-SOCIAL ATTENTION AND THE STRATEGIES FOR FAMILY INSERTION \\ EL CENTRO DE ATENCIÓN PSICOSOCIALY \\ LAS ESTRATEGIAS PARA LA INSERCIÓN DE LA FAMILIA
}

\author{
Guisela Schrank', Agnes Olschowsky²
}

\begin{abstract}
RESUMO
Esta pesquisa tem o objetivo de identificar as ações de saúde mental desenvolvidas no Centro de Atenção Psicossocial (CAPS) voltadas para a família no cuidado do indivíduo com sofrimento psíquico. Tratase de um estudo descritivo, analítico e do tipo estudo de caso com abordagem qualitativa. Para a coleta dos dados, foram realizadas a observação e a entrevista semi-estruturada com profissionais de um CAPS. Os resultados mostraram que o trabalho no CAPS só se concretiza pela parceria e participação familiar. $O$ atendimento individual, o grupo de família, a busca ativa, a visita domiciliar e as oficinas são estratégias realizadas no CAPS na efetivação da inserção da família. Nessa parceria, o vínculo aparece como fundamental na construção de caminhos menos sofridos e menos estigmatizados da vivência do sofrimento psíquico.
\end{abstract}

\section{DESCRITORES}

Saúde mental.

Serviços de Saúde Mental.

Família.

Enfermagem psiquiátrica.

\begin{abstract}
This research has the objective of identifying the mental health activities developed at Centers of Psycho-Social Attention (CAPSs) directed to the family in the care of individuals in psychological suffering. It is a descriptive, analytic survey of the case study type with a qualitative approach. Data collection was carried out through observation and semi-structured interviews with professionals of a CAPS. The results showed that the work at a CAPS becomes successful only when there is family partnership and participation. Individual sessions, family groups, active searches, home visits and workshops are strategies used at CAPSs for the effective insertion of the family. In this partnership, bonding appears as essential in the construction of less suffering and less stigmatized ways of psychical suffering.
\end{abstract}

\author{
KEY WORDS \\ Mental health. \\ Mental Health Services. \\ Family. \\ Psychiatric nursing.
}

\begin{abstract}
RESUMEN
Esta investigación tiene el objetivo de identificar las acciones de salud mental desarrolladas en el Centro de Atención Psicosocial (CAPS) volcadas para la familia en el cuidado del individuo con sufrimiento psíquico. Se trata de un estudio descriptivo, analítico del tipo 'estudio de caso' con abordaje cualitativo. Para la recolección de los datos, fueron realizadas la observación y la entrevista semiestructurada con profesionales de un CAPS. Los resultados mostraron que el trabajo en el CAPS sólo se concretiza con la asociación y participación familiar. La atención individual, el grupo de familia, la búsqueda activa, la visita domiciliaria, los talleres son estrategias realizadas en el CAPS para la efectividad de la inserción de la familia. En esta asociación, el vínculo aparece como fundamental para la construcción de caminos menos sufridos y menos estigmatizados de la vivencia del sufrimiento psíquico.
\end{abstract}

\section{DESCRIPTORES}

Salud mental.

Servicios de Salud Mental.

Familia.

Enfermería psiquiátrica.

\footnotetext{
*Extraído da dissertação "O Centro de Atenção Psicossocial e a inserção da família", Universidade Federal do Rio Grande do Sul, 2006. ${ }^{1}$ Enfermeira. Mestre em Enfermagem pela Universidade Federal do Rio Grande do Sul (UFRGS). Pelotas, RS, Brasil. guisela@pop.com.br ${ }^{2}$ Professora Adjunta da Escola de Enfermagem e do Programa de Pós-Graduação em Enfermagem da Universidade Federal do Rio Grande do Sul (UFRGS). Porto Alegre, RS, Brasil. agnes@enf.ufrgs.br
} 


\section{INTRODUÇÃO}

O primeiro contato que temos com o mundo é através dos nossos pais, pois é na família onde recebemos os primeiros valores, estabelecemos as primeiras relações afetivas, encontramos as respostas para as questões do dia-a-dia e compartilhamos nossas dúvidas, angústias e temores. A família tem fundamental importância para a formação do indivíduo, porque constitui a base, o alicerce principal para o desenvolvimento humano. Embora essa seja quase sempre representada por um conjunto de pessoas, ela também se constitui de relações afetivas estabelecidas entre os membros sanguíneos ou não(1).

Refletindo sobre nossa experiência em saúde mental, percebemos que quando um familiar adoece, ocorre uma mudança na convivência diária da família, causando ansiedade e preocupação, pois, na maioria das vezes, acreditamos que estamos imunes à doença. $\mathrm{O}$ adoecimento é um evento imprevisto que desorganiza o modo de funcionamento de uma família.

A situação amplia-se na vivência da doença mental, pois junto com a patologia psiquiátrica vem associados o estigma, o preconceito e a exclusão do indivíduo com sofrimen-to psíquico. Sentimentos como revolta, medo, vergonha, entre outros, fazem a complexidade desse fenômeno, pois o doente e a família, além do tratamento, devem apreender a lidar com o imaginário da incapacidade e periculosidade do louco, evitando os próprios preconceitos e os da sociedade ${ }^{(2)}$.

Assim, consideramos um desafio para os familiares cuidarem uma pessoa com doença mental, o que em parte justifica este estudo, pois requer enfrentamento de valores e sentimentos estigmatizados dos indivíduos e da sociedade os quais exigem, para este processo, uma mudança no olhar essa pessoa, passando a enxergá-la com capacidades e potencialidades, possibilitando a convivência com a diversidade.

Por muitos anos, a pessoa com diagnóstico de doença mental foi tratada em instituições que tinham como princípio terapêutico fundamental o isolamento(2).

Na atualidade, após os movimentos de crítica à instituição psiquiátrica, os hospitais psiquiátricos são substituídos por serviços de caráter extra-hospitalar como o CAPS (Centro de Atenção Psicossocial), Núcleo de Atenção Psicossocial (NAPS), Ambulatório de Saúde Mental, Hospital-dia, Serviços de Saúde Mental nos Hospitais Gerais, Centros de Convivência, Pensão Protegida, Lares Abrigados entre outros que buscam a reinserção do indivíduo com sofrimento mental na sociedade e o resgate da sua cidadania.

O CAPS é um serviço substitutivo de atenção em saúde mental que tem demonstrado efetividade na substituição da internação de longos períodos, por um tratamento que não isola os pacientes de suas famílias e da comunidade, mas que envolve os familiares no atendimento com a devida atenção necessária, ajudando na recuperação e na reintegração social do indivíduo com sofrimento psíquico.

Nossa vivência no CAPS nos motivou a estudar a família e seu doente, pois suas relações apontavam para o preconceito e desconhecimento dos familiares em relação à doença mental, fazendo-nos pensar: Será que a família dispõe de um preparo emocional e assistencial para acolher e cuidar de seu familiar adoecido? Como a família tem participado no resgate da cidadania do doente mental? A família tem recebido orientações suficientes para colaborar no cuidado de seu familiar?

Frente essa temática, pensamos ser necessário conhecer práticas assistenciais que envolvam tanto os usuários quanto os familiares para, desse modo, buscar a participação de ambos nas atividades do serviço desempenhadas por uma equipe multiprofissional comprometida em ajudar, dividindo com as famílias o tempo e a responsabilidade de cuidar, de apoiar nas dificuldades e de oferecer suporte e atenção.

Uma das mudanças proporcionadas com a reestruturação da assistência psiquiá trica foi a de possibilitar que o doente mental permaneça com sua família, mas para que este convívio seja saudável e positivo, é preciso que o serviço esteja inserido numa rede articulada de apoio e de organizações que se proponham a oferecer um continuum de cuidados $^{(2)}$.

O comprometimento da família no cuidado do doente exige uma nova organização familiar e aquisição de habilidades que podem, num primeiro momento,desestruturar as atividades diárias dos familiares. Porém, essa responsabilidade do familiar com seu adoecido também é positiva, pois além de intensificar suas relações, o familiar torna-se um parceiro da equipe de saúde para cuidar do usuário, sendo facilitador nas ações de promoção da saúde mental e de inserção do indivíduo em seu meio.

Muitas vezes, o familiar responsável concentra sua dedicação e seu tempo no cuidado da pessoa com sofrimento psíquico, o que pode levar a transformações na sua vida, como dificuldades no trabalho e diminuição do lazer ${ }^{(3)}$. Pensamos que a equipe de saúde mental deve estar aten-ta e comprometida com essa problemática: a dificuldade/complexidade do cuidado da família e do usuário, buscando construir dispositivos de apoio e mecanismos que facilitem a participação e a integração da família.

Nesta multiplicidade de sujeitos envolvidos, a família se destaca pelo seu papel de cuidadora e por ser, muitas vezes, o elo mais próximo que os usuários têm com o mundo ${ }^{(4)}$. 
Entendendo a família como uma unidade de cuidado, ou seja, cuidadora nas situações de saúde e doença dos seus membros, compete aos profissionais apoiá-la, orientá-la e fortalecê-la quando esta se encontrar fragilizada. Assim, o tratamento não se restringe apenas a medicamentos e eventuais internações, mas, também a ações e procedimentos que visem a uma reintegração familiar, social e profissional, bem como a uma melhoria na qualidade de vida do doente e do familiar ${ }^{(5)}$.

Frente a problemática em relação aos familiares e a pessoa com sofrimento psíquico, apresentamos a necessidade de repensar o cuidado numa perspectiva assistencial que foge do modelo tradicional centrado na cura da doença.

\section{OBJETIVO}

Identificar as ações de saúde mental desenvolvidas no CAPS voltadas para a família no cuidado do indivíduo com sofrimento psíquico.

\section{MÉTODO}

Este estudo se caracterizou como sendo uma pesquisa descritiva, analítica e do tipo estudo de caso com abordagem qualitativa. Optamos pela estratégia de pesquisa estudo de caso, pois investiga um fenômeno contemporâneo dentro de seu contexto da vida real, especialmente quando os limites entre o fenômeno e o contexto não estão claramente definidos ${ }^{(6)}$. 0 estudo de caso também possibilita a observação da realidade concreta em funcionamento com acesso a informações privilegiadas e detalhadas.

Entendendo o trabalho realizado no CAPS como coletivo e em movimento, o qual se constitui e se transforma para satisfazer necessidades dos diferentes atores, buscamos, por meio do estudo de caso, conhecer a multiplicidade das ações e situações realizadas ou não para a inserção da família no cuidado em saúde mental.

O universo eleito para a coleta dos dados foi o Centro de Atenção Psicossocial II Fragata (CAPS II Fragata) localizado na cidade de Pelotas - RS. A escolha foi intencional, porque esse serviço apresenta-se estruturado de acordo com as políticas atuais preconizadas pela assistência de saúde mental no Brasil, possibilitando assim, explorar as questões desta pesquisa.

Definimos a equipe multiprofissional como sujeitos do estudo, cujo critério de escolha foi a representação de um profissional por categoria e, nos casos que houveram mais de um profissional, o critério foi o de maior tempo de serviço no CAPS, totalizando 10 (dez) sujeitos da pesquisa: um enfermeiro, um auxiliar de enfermagem, um psicólogo, um psiquiatra, um assistente social, um artista formado em Artes Plásticas, um artista formado em Música, um professor de Educação Física, um recepcionista e um artesão.
Os instrumentos utilizados para a coleta de dados foram: a observação e a entrevista semi-estruturada.

O projeto de pesquisa foi aprovado pelo Comitê de Ética em Pesquisa da Universidade Federal do Rio Grande do Sul sob o parecer número 2005438.

Como técnica para a análise dos dados, propusemos a Análise Temática que "consiste em descobrir os núcleos de sentido que compõem uma comunicação cuja presença ou freqüência signifiquem alguma coisa para o objetivo analítico visado"(7).

Esta análise apresentou três etapas:

a) Pré-Análise: primeiramente foi realizada a leitura flutuante, que consistiu na leitura exaustiva e organização do material de acordo com a representatividade, homogeneidade e pertinência, objetivando responder questões teoricamente colocadas. Nesta fase, foram categorizados e codificados os conceitos teóricos mais gerais da análise com palavras chaves ou frases.

Tivemos a clareza de que dados não falam por si mesmos, são construídos com questionamentos e fundamentação teórica, exigindo inúmeras leituras do material para identificar as idéias centrais das falas dos entrevistados.

b) Exploração do Material: nesta etapa, foram realizadas a classificação e a agregação dos dados, identificando as categorias que comandarão a especificação dos temas.

Assim, constituíram-se os seguintes temas: inserção da família, estratégias para a inserção familiar e a vivência do estigma da doença mental.

c) Tratamento dos Resultados Obtidos e Interpretação: na interpretação dos resultados, procuramos articular os temas encontrados com o referencial teórico e objetivo do trabalho.

\section{RESULTADOS}

O CAPS II Fragata é reconhecido como um serviço de atenção em saúde mental ordenado pela lógica não manicomial, onde os recursos extra-hospitalares são o suporte de um modelo de tratamento centrado na relação terapeuta-paciente, sustentado pelo respeito aos direitos de cidadania das pessoas com sofrimento psíquico.

Este serviço orienta-se de acordo com a modalidade definida na Portaria no 336 de 2002, a qual determina que o CAPS II é um serviço de atenção psicossocial com capacidade operacional para atender uma população entre 70.000 (setenta mil) e 200.000 (duzentos mil) habitantes, com o funcionamento em dois turnos, das oito às 18 (dezoito) horas, cinco dias úteis na semana, podendo comportar um terceiro turno com funcionamento até às 21 (vinte $e$ uma) horas. O serviço, com esta modalidade deve desenvolver as seguintes atividades: atendimento individual, em grupo e oficinas, visitas domiciliares, atividades comunitárias e refeições para os usuários assistidos no serviço(4). 
A equipe multiprofissional do CAPS é composta, atualmente, por dois psiquiatras, duas enfermeiras, dois técnicos de enfermagem, uma auxiliar de enfermagem, uma assistente social, três psicólogas, dois educadores físicos, uma artista plástica, uma artesã, três oficiais administrativos, três merendeiros, três guardas-municipais e um auxiliar para serviços gerais. $O$ trabalho da equipe multiprofissional do CAPS é orientado de acordo com a interdisciplinaridade, ou seja, busca uma descentralização do saber e do poder pela divisão das responsabilidades, de acordo com a peculiaridade de cada profissão que compõe a equipe.

Com base no modo psicossocial, o CAPS preconiza, como uma das suas metas, a desinstitucionalização, amparada por um processo prático de desconstrução do modelo tradicional da atenção psiquiátrica, propondo um conjunto de dispositivos que possibilitam a construção e a invenção de novas perspectivas de vida e subjetividade, com base não apenas em diagnósticos e prognósticos da doença mental, mas sim, na complexidade que envolve o indivíduo na sua dimensão psíquica e nas suas relações com o meio em que vive. Assim, este serviço busca a reinclusão das pessoas com sofrimento psíquico na família, na comunidade e na visa produtiva, através da recuperação da auto-estima e reestruturação de vínculos.

O CAPS tem orientado suas práticas de acordo com o modo psicossocial, considerando a família como a base fundamental no processo de reinserção da pessoa com sofrimento psíquico na sociedade e no próprio meio fami$\operatorname{liar}^{(4)}$. Configuram-se como atividades de atenção à família no CAPS Fragata o acolhimento, a visita domiciliar, o atendimento individual e em grupo aos familiares, buscando assim, implementar essa parceria e a interação entre os atores desse processo.

Assim, o CAPS busca o redirecionamento da assistência nos responsáveis do tratamento no contexto da reforma psiquiátrica brasileira por meio da inserção familiar, pois

é reconhecido o valor da participação da família na assistência ao doente mental, para o alcance de melhor qualidade de vida do doente e da família(8)

A parceria com a família se constitui em estratégias de mobilização e comprometimento para lidar com a loucura no território, proporcionando a potencialidade de trocas entre o serviço, usuário e sua rede social|(3).

Desse modo, apresentamos uma das temáticas emergidas nesta pesquisa: estratégias de inserção familiar para o cuidado da pessoa que sofre psiquicamente. Os entrevistados trazem em suas falas as seguintes estratégias que oportunizam a parceria da família no cuidado: grupo de família, atendimento individual, busca/chamamento, oficinas e a visita domiciliar.

Dentre estas estratégias, o grupo de família apareceu como a principal atividade:
[...] não tem propriamente, assim, atividades para os familiares porque são muitos pacientes. Então, tem mais atividades para os pacientes. Muito difícil acompanhante fazer alguma coisa, mais são os pacientes. Mas com os familiares, até o momento, só o grupo de família (EP2).

O grupo de família é a atividade realizada no CAPS exclusivamente para os familiares. Esse grupo possibilita uma interação e compartilhamento das vivências entre os participantes, constituindo um espaço de troca de conhecimento e de experiências,

importante ferramenta para ampliar a capacidade de lidar com os problemas, assim como tem permitido que um familiar possa se abrir para o discurso do seu companheiro(9).

Essa troca de conhecimentos entre os atores envolvidos no grupo aparece como um processo de

[...] feedback, assim, o que está ajudando o CAPS, mas também, no que a família está precisando mais de ajuda. Não só em relação ao usuário, mas em relação a essas pessoas que vivem com ele, familiares, independendo se é pai, mãe, no ambiente que ele convive ali, que ele possa saber mais como lidar com a pessoa, porque que é diferente, qual é a melhor maneira de tratar para que todo o ambiente fique mais harmonizado, para que as coisas melhorem dentro do serviço (EP4).

Os integrantes do grupo têm a possibilidade de compartilhar as situações vivenciadas com o usuário, assim como, os profissionais têm a oportunidade de orientar e esclarecer o familiar quanto às situações da vida cotidiana, destacando o dispositivo grupal como

estratégia privilegiada por sua capacidade diferenciadora, intercessora nos processos contemporâneos individualizados de experimentação da subjetividade ${ }^{(10)}$.

A vivência em grupo possibilita o senso de inclusão, valorização e identificação nas experiências coletivas dos problemas de saúde. Além disso, pode favorecer a escuta e, na medida em que se dispõe de vários olhares acerca de uma mesma problemática, a capacidade resolutiva mutuamente se reforça ${ }^{(11)}$.

Desse modo, o cuidado produzido no grupo é resultado de uma força coletiva cuja responsabilidade também se encontra nas mãos do coordenador do grupo, o qual deve ter um

olhar atento à singularidade dos sujeitos, o que implica uma atenção personalizada dirigida à construção de um processo terapêutico que leve em conta as particularidades de cada situação(9).

Assim, a participação da família no grupo constitui uma oportunidade de

[...] procurar trazer o problema da família para motivar os familiares também, porque tem muitas pessoas que se sentem sobrecarregadas com o paciente, e o CAPS vai incentivar para que o familiar faça parte do processo de tratamento (EP9). 
Entretanto, para que a participação familiar no serviço seja efetiva, além da disposição e da vontade de participar, é necessário que haja o vínculo entre profissionais e família, comunidade e usuário, sendo um aspecto relevante no cuidado em saúde mental, pois nas práticas de atenção psicossocial a relação entre os técnicos e familiares se intensifica no compartilhamento e organização de novas formas de viver na sociedade. A idéia de responsabilização dos atores sociais envolvidos na atenção psicossocial, remete para a parceria com a comunidade, visando o grau de autonomia e ações norteadas por uma ética de solidariedade ${ }^{(12)}$.

O vínculo pode alicerçar uma relação compromissada entre a equipe, usuário e família, propiciando uma convivência que deve ser sincera e de responsabilidade. Assim, o estabelecimento de vínculos vai facilitar a parceria, pois através do relacionamento teremos uma ligação mais humana, mais singular que vai buscar um atendimento que melhor se aproxime às necessidades dos usuários e famílias, implementando uma atuação da equipe mais sensível para a escuta, compreensão de pontos de vulnerabilidade e a construção de intervenções terapêuticas individuais, respeitando a realidade específica e tornando a parceria como algo possível e concreto.

Convocar a família para assumir a responsabilidade do cuidado do usuário em conjunto com a equipe, exige mais do que um redirecionamento das práticas, exige comprometimento e responsabilidade para a construção de um cuidado que é coletivo desses atores em promover e manter a autonomia do usuário, reconquistar sua cidadania e seu espaço na sociedade, construindo uma responsabilização e um cuidado coletivo.

Participar, estar próximo, junto, fazer em conjunto se constituem práticas construídas no dia a dia da vivência do sofrimento psíquico. Essa relação, esse vínculo, reverte-se em confiança, em caminhos menos sofridos, menos estigmatizados e mais partilhados para inventar novos modos de atenção em saúde mental.

O vínculo ao serviço entra também como um recurso de vencer as resistências da família nessa parceria, pois no convívio diário, na troca das informações, no esclarecimento das dúvidas, na descoberta de diferentes modos de fazer o cuidado em saúde mental é que vão estruturarse propostas de atenção, de agir, de considerar, de aceitar as individualidades dos usuários e das famílias. Neste sentido, trabalhar no CAPS requer dos profissionais habilidades e motivação para construir trocas de conhecimentos teóricos e práticos entre a equipe, assim como, compreender e acolher a vivência dos familiares e usuários.

Portanto, as atividades de inserção familiar

[...] são grupais, individuais e através das visitas. E no dia a dia, também tem familiar que acompanha o usuário no CAPS (EP1)
Nesse sentido, a participação da família como protagonista das estratégias de cuidado e reabilitação, inserida nas diversas atividades do CAPS como nas assembléias, festas e grupos, constituem-se de ações que podem possibilitar a construção de laços, em que o usuário e a família são escutados e acolhidos no sofrimento trazidos por eles. Assim, a partir dos relatos dos entrevistados, identificamos as atividades das oficinas, o atendimento individual, a visita domiciliar, a busca ativa e o grupo de família como estratégias de integração entre equipe, família e usuário.

As oficinas são atividades identificadas como estratégia para a inserção da família no CAPS, pois, ao mesmo tempo em que pode oportunizar ao usuário meios para a sua reinserção social e o rompimento do isolamento através da vivência subjetiva, permitirá que o trabalho realizado nas oficinas se estenda à família, no sentido de produzir territórios existenciais que promovam a reinvenção da vida em seus aspectos mais cotidianos ${ }^{(13)}$.

Nesse contexto, a atividade das oficinas possibilita a reconquista ou conquista dos usuários em relação à sua participação na sociedade com autonomia e reconhecimento de um cidadão. Esse trabalho requer ajuda da família, pois o usuário precisa sentir-se amparado para produzir conexões entre os diversos aspectos componentes do cotidiano, como o trabalho, lazer, amigos, refletindo na credibilidade e amadurecimento da própria família nesse processo.

A família não necessita estar presente nas atividades das oficinas para constituir uma estratégia da sua participação no cuidado, porque os resultados do trabalho realizado nas oficinas irão, de uma certa forma, refletir na atitude do usuário em casa e na sociedade, manifestando suas potencialidades e capacidades trabalhadas, conforme as falas a seguir:

\section{[...] normalmente não tem tanta participação dos familiares} nas oficinas, porque as oficinas são mais para os pacientes. Mas tem alguns casos que o familiar participa das oficinas (EP6).

[...] participam das oficinas, os familiares junto com os pacientes. Alguns, não são todos que participam do trabaIho do CAPS em conjunto com as oficinas, com o que tiver, com os afazeres do CAPS (EP3).

As oficinas realizadas no CAPS caracterizam-se por ser um espaço que possibilita o contato dos usuários com atividades manuais, explorando a criatividade e a inventividade através do aprendizado das técnicas e dos saberes, sendo coordenadas por profissionais habilitados na área ${ }^{(5)}$.

As atividades das oficinas também podem promover a participação efetiva da família, mas para isso, elas devem ser caracterizadas como um dispositivo assistencial do modo psicossocial de organização horizontalizada e com a participação, além dos usuários, de seus familia- 
res e de profissionais de diversas áreas, incorporando um espaço terapêutico a partir do momento em que possibilitem aos sujeitos que nelas participam um lugar de fala, expressão e acolhimento(14).

Desse modo, os discursos devem ser materializados nas práticas assistenciais para que possamos considerar a oficina como uma estratégia global e não-técnica, permitindo o questionamento das Políticas de Saúde Mental para que haja uma ruptura radical com o modo asilar. Porém, essa ruptura irá se concretizar no momento em que todos os atores envolvidos - profissionais, usuários, familiares e comunidade - forem englobados nesse processo ${ }^{(10)}$.

Afinal, oportunizar a produção do conhecimento e do social, no sentido de proporcionar espaços de atuação do usuário nas dimensões individuais, coletivas e culturais, faz com que as oficinas estabeleçam um modo de cuidar e de promover a subjetividade do usuário, o que inclui, nessa questão, a parceria da família e equipe como um dos aspectos essenciais para o início e manutenção desse processo.

Já a atividade da visita domiciliar aparece como outra estratégia para promover a participação familiar no trabalho conjunto com a equipe. Através dessa atividade, a equipe tem a possibilidade de conhecer a dinâmica familiar e compreender como ela se relaciona no seu meio, além de oportunizar uma interação do profissional com essa família, visando à busca de uma parceria no cuidado do usuário e possibilitando um atendimento domiciliar, pois

[...] quando tu vai no domicílio, tu também tem contato com o familiar. Então, se tem um familiar que não vem no CAPS, mas aí tu faz uma visita domiciliar, tu também tem esse contato [...]. Eu já fiz várias visitas domiciliares e a gente também conhece a realidade daquela família (EP7).

A visita domiciliar é uma prática assistencial que se constitui como essencial para o cuidado do usuário e família, porque ela proporciona a oportunidade de acoIher esses atores no meio em que vivem. Isso é importante por oferecer modos de cuidados alternativos àqueles centrados na instituição, possibilitando o conhecimento das reais necessidades do usuário e familiares.

Além disso, é uma atividade em que a equipe também pode utilizar para identificar as famílias que não participam das atividades do CAPS ou que demonstram dificuldades em cuidar do usuário, oportunizando uma aproximação que possa gerar um trabalho conjunto entre equipe e família, constituindo-se, desse modo, como uma estratégia para buscar a parceria da família no cuidado. Através das visitas domiciliares, os profissionais têm a oportunidade de fundamentar suas intervenções com base na realidade experienciada juntamente com a família.

O cenário no domicílio exige, dos profissionais, criatividade, solidariedade e respeito pelas escolhas do usuá- rio e família, desse modo, a visita domiciliar é uma estratégia de atenção que pode abrir espaços de cuidado, de interlocução, de acolhimento, de aceitação e de possibilidade.

A visita domiciliar também é uma atividade que possibilita ao profissional intervir e compreender o cuidado desenvolvido pela família, o qual tem como "finalidade preservar a vida de cada um de seus membros, para alcançar o desenvolvimento pleno de suas potencialidades, de acordo com suas próprias possibilidades e as condições do meio onde ela vive"(15).

Entendemos que este recurso deve ser sistemático e contínuo na proposta de trabalho do CAPS, pois abre uma porta singular para a convivência e a parceria entre equipe e família.

A busca/chamamento também são estratégias de inserção familiar, realizada através das visitas domiciliares, de bilhetes e telefonemas para a família:

[...] a gente insiste muito, manda bilhete, telefona, a gente sempre usa alguns recursos assim, e sempre insistindo muito (EP5).

[...] a gente acha que é bom que eles vêm outro dia participar de outras atividades. Pega o telefone e liga para as pessoas que não costumam freqüentar o CAPS. O usuário diz: - ele não vai me levar, ele tem dificuldade de ir. Então, a gente tenta conversar para ver de que forma pode se fazer (EP4).

A busca mostra um sentido de comprometimento e responsabilidade conjunta da equipe. É um modo de estar com a família quando as mesmas se apresentarem distantes do tratamento, ou com dificuldades no cuidado ou até mesmo quando a família não consegue conciliar seu horário com o do funcionamento do CAPS. Possibilita um outro espaço de expressar compromisso, de acolhimento das necessidades e dificuldades, ultrapassando a estrutura física das práticas assistenciais.

O CAPS possui recursos terapêuticos grupais e individuais para os usuários, familiares e comunidade. Dentre essas atividades, o atendimento individual revela uma prática terapêutica que possibilita uma atenção à família com a escuta e o acolhimento do sofrimento, o que oportuniza a promoção da saúde, assim como, se constitui de uma estratégia para a equipe buscar a parceria da família, mostrando que o cuidado do usuário se faz com um trabalho conjunto entre equipe e família.

$\mathrm{O}$ atendimento individual possibilita as pessoas envolvidas um contato mais direto e preciso, propiciando uma conversa resolutiva das dificuldades encontradas pelos profissionais, ou familiares e usuários. Quando há necessidade de compreender atitudes, questionar alguma situação, ou seja, quando o assunto a ser abordado envolve a intimidade, a vida particular, é proposto o atendimento individual. Esse atendimento também aparece como uma estratégia para a equipe assistir a família, pois 
[...] o CAPS é aberto, as pessoas da equipe são abertas quando o familiar necessita de atendimento, atendimento individual (EP8).

Oferecer atendimento quando o familiar solicita também se faz necessário para cuidar dessa família, mas não se constitui em uma estratégia de inserção familiar no cuidado, apenas ao fato da equipe manter-se aberta para o atendimento. A concretização da "inserção da família exige uma atitude de compromisso e responsabilização da equipe com a sua efetivação"(16).

Atividades como festas comemorativas (festa junina, festa de natal), assim como, eventos realizados para promover a integração família-usuário-comunidade-técnico, também são instrumentos facilitadores para o trabalho conjunto da família com a equipe:

\begin{abstract}
O familiar participa do grupo de família [...], mas os familiares participam de tudo, tem festas, tem atendimento quando a gente chama a família, tem atendimento individual também, tem visitas domiciliares, essa busca. Mas aqui no CAPS, no serviço, é o grupo de famílias, mas a gente usa de outros recursos, no caso, de telefones, visita domiciliar, pedir a participação em festas, em eventos, quando tem. É uma forma de chamá-los (EP5).
\end{abstract}

Todas as atividades desenvolvidas para promover a integração da família com os usuários, profissionais e outros familiares são essenciais, pois além do aprimoramento das relações, é um espaço que possibilita a troca de experiência e de ajuda entre as pessoas que vivenciam a mesma situação do processo saúde-doença.

A participação da família nos eventos realizados com os usuários também é uma oportunidade da equipe conhecer a família e convidá-la para visitar o serviço e participar de uma atividade, demonstrando que tal atitude é fundamental para o cuidado do usuário, como forma de motivação e valorização.

O grupo de família, o atendimento individual, a busca/ chamamento, as oficinas e a visita domiciliar são estratégias de inserção familiar facilitadoras do trabalho do CAPS, caracterizando-se como intervenções em movimento, exigindo dos profissionais negociação e interlocução nesse processo de parceria que deve ser criado, criticado e revisto diariamente.

Desejo, vontade, persistência são atributos necessários na equipe do CAPS para promover a parceria que se constitui através da acolhida e do vínculo, ou seja, dar créditos, dar ouvidos, aceitar e fazer novos nexos e novos significados no relacionamento com a família.

\section{CONSIDERAÇÕES FINAIS}

No presente estudo, um CAPS que pressupõe seu trabaIho no modo psicossocial deve, fundamentalmente, considerar que essa proposta só se concretiza através da parceria e da participação familiar. Esse processo não é estável e não é fácil, exigindo do usuário, da família e da equipe: vontade, credibilidade e desejo de conquista.

A inserção da família acontece no compartilhamento da responsabilidade pelo cuidado integral do usuário, sendo condição sine qua non para possibilitar uma interrelação congruente com as necessidades do usuário e família.

No CAPS, a inserção da família também se constitui como uma dinâmica singular, na qual esse relacionamento deve apoiar-se na desconstrução da idéia de estar só no enfrentamento do sofrimento psíquico, integrando, acolhendo, cuidando e incluindo os atores dessa relação nos espaços cotidianos da vida: trabalho, lazer, moradia entre outros.

Essa possibilidade de parceria também sofre dificuldades, devendo a família parceira ser olhada também como objeto de intervenção da equipe de saúde mental, pois não se cuida sem família e, para tal, é exigido um olhar ampliado para todos os recursos encontrados nela própria e na sua rede social.

A participação familiar no serviço e nos cuidados com o usuário pode possibilitar uma aproximação das relações afetivas e um rompimento de preconceitos como a incapacidade e a periculosidade, os quais haviam ajudado no processo de afastamento do convívio social. Para essa efetivação, além da participação familiar, também é necessário que os profissionais estejam cientes da importância familiar neste processo, assim como, acreditarem e se responsabilizarem por essa participação.

Nesse sentido, a equipe de saúde tem papel fundamental na inserção da família no cuidado do usuário, pois deve buscar potencialidade/criatividade na construção de um ambiente e condições que favoreçam a participação familiar. Para isso, os profissionais devem acreditar nessa parceria e compreender que esse processo está em constante mudança, ou seja, a inserção familiar não é estável, muito menos fácil. Ao contrário, exige que os profissionais tenham perseverança, vontade e credibilidade para promover essa integração, fundamentada pelo desejo de conquista. Além disso, o trabalho entre equipe e família deve ser conjunto, o que requer o compartilhamento da responsabilidade e do compromisso para a concretização de uma assistência integral ao usuário.

Trabalhar no CAPS em conjunto com as famílias, requer dos profissionais uma ação cotidiana, orientação, informação, esclarecimento, troca constante de modos de lidar e transformar as diferentes trajetórias de vida.

O trabalho conjunto do CAPS com a família é necessário para o cuidado não ser fragmentado, necessitando de continuidade e cumplicidade entre os envolvidos em todos os espaços sociais possíveis. Assim, as estratégias como o atendimento individual, o grupo de família, a bus- 
ca ativa, a visita domiciliar, as oficinas são atividades realizadas no CAPS que tem como objetivos: orientar, esclarecer, facilitar, incentivar e apoiar a família nessa proposta de trabalho, objetivando, desse modo, a convivência e o respeito frente à experiência do sofrimento psíquico.

Essa parceria entre equipe e família constitui-se através da formação de vínculos, ou seja, o relacionamento nas práticas assistenciais do CAPS é construída na proximidade do viver o dia a dia do sofrimento psíquico.

\section{REFERÊNCIAS}

1. Wright LM, Leashey M. Enfermeiras e famílias: um guia para avaliação e intervenção na família. São Paulo: Roca; 2004.

2. Amarante $P$, coordenador. Saúde mental, políticas e instituições: programa de educação à distância. Rio de Janeiro: FIOCRUZ; 2003.

3. Rosa LCS. Transtorno mental e o cuidado na família. São Paulo: Cortez; 2003.

4. Brasil. Ministério da Saúde. Departamento de Ações Programáticas Estratégicas. Saúde mental no SUS: os centros de atenção psicossocial. Brasília; 2004.

5. Elsen I. Cuidado familial: uma proposta inicial de sistematização conceitual. In: Elsen I, Marcon SS, Silva MRS, organizadoras. O viver em família e sua interface com a saúde e a doença. 2a ed. Maringá: EDUEM; 2004. p. 19-28.

6. Yin RK. Estudo de caso: planejamento e métodos. Trad. de Daniel Grassi. 3ạ ed. Porto Alegre: Bookman; 2005.

7. Minayo MCS. O desafio do conhecimento: pesquisa qualitativa em saúde. 8a ed. São Paulo: Hucitec; 2004.

8. Spadini LS, Souza MCBM. A doença mental sob o olhar de pacientes e familiares. Rev Esc Enferm USP. 2006; 40 (1): 123-7.

9. Melman J. Família e doença mental: repensando a relação entre profissionais de saúde e familiares. São Paulo: Escrituras; 2001.
O vínculo reveste-se em confiança, em caminhos menos sofridos e menos estigmatizados na inserção da família no cuidado, bem como, no engajamento de novas parcerias para dentro do território.

Usuário, família, equipe e território são espaços de vida, de sentimentos, que nos abrem caminhos possíveis para a implementação da parceria no cuidado em saúde mental.

10. Barros RB. O dispositivo grupal no processo da Reforma Psiquiátrica no Brasil. In: Amarante $P$, organizador. A loucura da história. Rio de Janeiro: FIOCRUZ; 2000. p. 277-83.

11. Dall'Agnol CM, Ciampone MHT. Grupos focais como estratégia metodológica em pesquisas na enfermagem. Rev Gaúcha Enferm. 1999;20(1):5-25.

12. Silva MBB. Responsabilidade e Reforma Psiquiátrica brasileira: sobre a produção de engajamento, implicação e vínculo nas práticas de atenção psicossocial [dissertação]. Rio de Janeiro: Instituto de Medicina Social, Universidade Estadual do Rio de Janeiro; 2004.

13. Rauter C. Oficinas para quê? Uma proposta ético-estético-política para oficinas terapêuticas. In: Amarante P, coordenador. Ensaios: subjetividade, saúde mental, sociedade. Rio de Janeiro: FIOCRUZ; 2000. p. 267-77.

14. Lappan-Botti NC, Labate RC. Oficinas em saúde mental: a representação dos usuários dos serviços de saúde mental. Texto Contexto Enferm. 2004;13(4):519-26.

15. Delgado JA. A família vivenciando situações de saúdedoença: um conhecimento em construção. In: Elsen I, Marcon SS, Silva MRS, organizadoras. O viver em família e sua interface com a saúde e a doença. 2a ed. Maringá: EDUEM; 2004.

16. Wetzel C. Avaliação de serviço em saúde mental: a construção de um processo participativo [tese]. Ribeirão Preto: Escola de Enfermagem de Ribeirão Preto, Universidade de São Paulo; 2005. 